\title{
THE EFFECT OF ACUTE ELEVATION OF THE PLASMA CHLO- RIDE CONCENTRATION ON THE RENAL EXCRETION OF BICARBONATE DURING ACUTE RESPIRATORY ACIDOSIS 1
}

\author{
By JAMES G. HILTON, NICHOLAS E. CAPECI,2 GEORGE T. KISS,2 OSCAR R. \\ KRUESI, 3 VINCENT V. GLAVIANO, 2 AND RENE WEGRIA
}

(From the Department of Medicine, St. Luke's Hospital, New York, N. Y.)

(Submitted for publication November 1, 1955 ; accepted January 16, 1956)

It has been postulated recently that renal bicarbonate reabsorption is entirely dependent on the exchange of hydrogen ions, derived from the dissociation of carbonic acid within the cells of the renal tubule, for the fixed base of filtered bicarbonate in the tubular urine (1-3). According to this theory, an elevation of the $\mathrm{CO}_{2}$ tension of the extracellular fluid results in an increase in the rate of bicarbonate reabsorption because it leads to an increase in the rate of hydrogen ion secretion.

Earlier studies, however, indicate that chloride reabsorption may interfere with bicarbonate reabsorption presumably because of competition between these two ions for some common transport mechanism in the proximal tubule (4). Since plasma $\mathrm{PCO}_{2}$ was apparently within normal range in those experiments, it was thought of interest to study the effect of hyperchloremia on bicarbonate reabsorption in the presence of an elevated extracellular $\mathrm{pCO}_{2}$.

Our results indicate that under these circumstances the rate of bicarbonate reabsorption does not depend entirely on the $\mathrm{CO}_{2}$ tension, but may, in part, depend upon the rate of chloride ion reabsorption.

\section{METHODS}

Normal adult mongrel female dogs were anesthetized by the intravenous administration of 0.46 to $0.62 \mathrm{mg}$. of sodium pentobarbital per kilogram of body weight. The trachea was cannulated with a "Y"-shaped glass tube, the two free arms of which served as inspiratory and expiratory airways by means of flutter valves. The animals breathed spontaneously throughout the entire experiment. The abdomen was opened by a midline in-

\footnotetext{
1 Supported by grants-in-aid from the New York Heart Association and the American Heart Association.

2 Fellow of the New York Heart Association.

${ }^{3}$ Frances H. Zabriskie Fellow, St. Luke's Hospital.
}

cision and each ureter cannulated with a polyethylene tube. The abdomen was then closed by a continuous silk suture and the polyethylene tubes brought through the suture line, care being taken not to kink the ureters and tubes. Urine was collected directly under mineral oil contained in a graduated cylinder.

During the successive periods of study, the dog breathed first room air, then a mixture of $\mathrm{CO}_{2}$ and air containing 10 per cent of $\mathrm{CO}_{2}$.

The different solutions were administered at desired rates by means of a constant-speed Bowman pump via a cannulated brachial vein. As the operative procedure was begun, the animal was given intravenously within a 5 to 24-minute period $400 \mathrm{ml}$. of a 0.15 molar sodium bicarbonate solution containing $0.375 \mathrm{Gram}$ per cent of creatinine. Then a sustaining infusion containing from 0.93 Gram per cent of $\mathrm{NaHCO}_{3}$ to 1.175 Gram per cent of $\mathrm{NaHCO}_{3}$ ( 0.11 to 0.14 molar solution) was administered at rates varying between 6.4 and $18.5 \mathrm{ml}$. per minute. This infusion also contained an amount of creatinine such that the dog received $15 \mathrm{mgm}$. of creatinine per minute. When the operative procedures were completed, a fifteen to thirty-minute equilibration period was allowed. Then control determinations were made, the animal breathing room air and receiving the sustaining infusion. The dog then inhaled the air- $\mathrm{CO}_{2}$ mixture and after thirty minutes of administration of this mixture, a second set of determinations was made, the dog still receiving the same sustaining infusion as during the first set of determinations. Chloride loading was then accomplished by the rapid administration of a priming injection of 30 to $45 \mathrm{ml}$. of a $3.33 \mathrm{Gram}$ per cent of sodium chloride solution. The sustaining infusion was then changed to one containing 1.68 Gram per cent to 2.3 Gram per cent of $\mathrm{NaHCO}_{3}(0.2 \mathrm{M}$ to $0.27 \mathrm{M})$ and 4.35 Gram per cent to $7.6 \mathrm{Gram}$ per cent of $\mathrm{NaCl}$. It was delivered at rates of from 3.2 to $6.4 \mathrm{ml}$. per minute. After thirty minutes of administration of this infusion, determinations were again made. In some experiments the first control period (room air breathing) was omitted. The exogenous creatinine clearance was taken as equal to the glomerular filtration rate (GFR).

Arterial blood samples were obtained at the midpoint of each clearance period from a needle inserted into a femoral artery. The blood was collected anaerobically and rendered incoagulable with heparin. The $\mathrm{pH}$ of the whole blood was determined immediately on a $0.5-\mathrm{ml}$. 


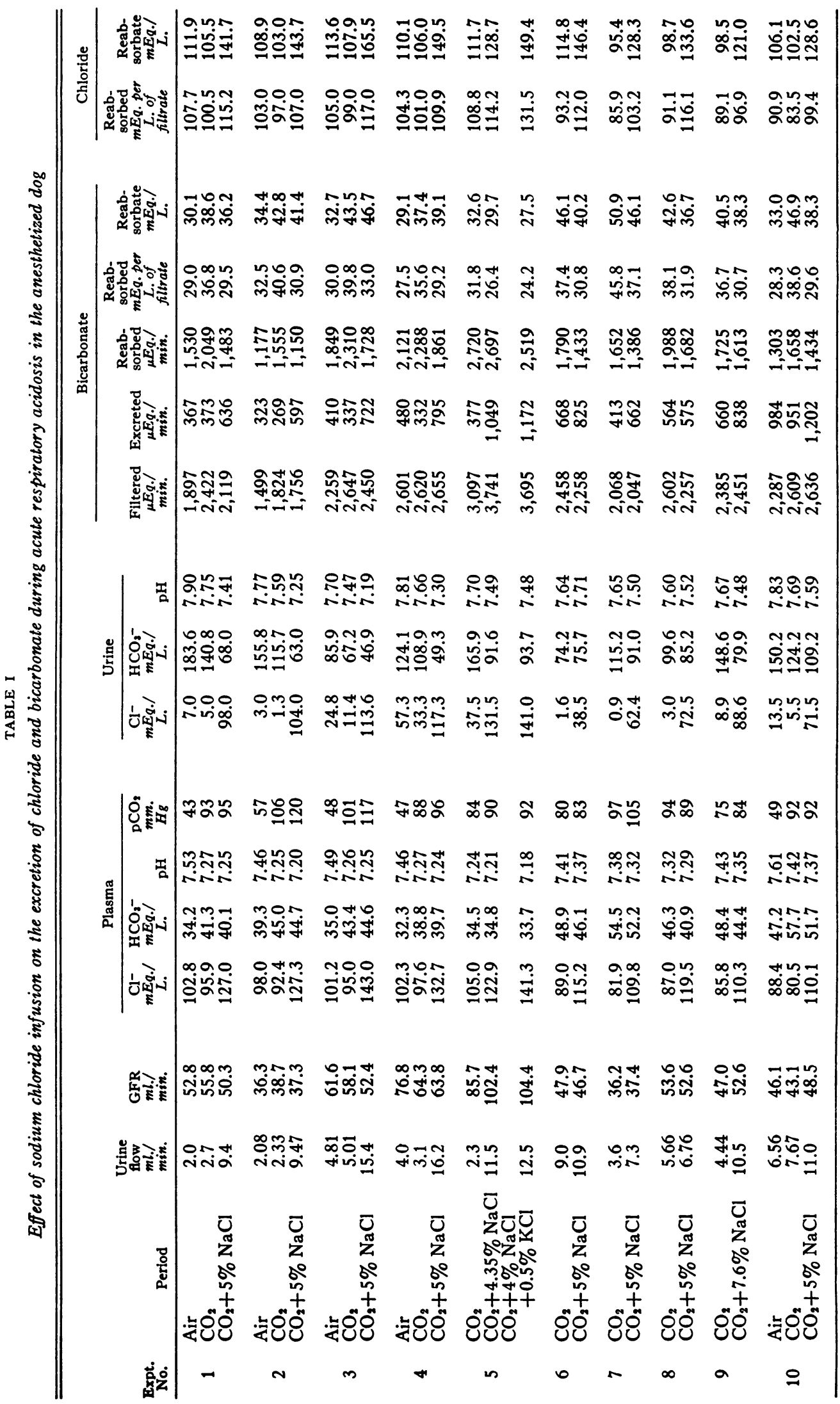


portion of the sample and the rest of the sample was delivered under mineral oil into a centrifuge tube and centrifuged. The plasma was then immediately analyzed for $\mathrm{CO}_{2}$ content.

Creatinine was determined in diluted urine and protein free filtrates of plasma by the method of Kennedy, Hilton, and Berliner (5). Total $\mathrm{CO}_{2}$ in plasma and urine was determined by the manometric extraction technique of Van Slyke and Neill (6). The pH of the whole blood and urine was determined anaerobically at room temperature with a Beckman model $\mathrm{G}$ pH meter equipped with a syringe-type glass electrode. A correction factor (7) of $0.014 \mathrm{pH}$ units per degree of difference between room and body temperatures was used in the calculation of the $\mathrm{pH}$. Concentrations of bicarbonate and dissolved $\mathrm{CO}_{2}$ were calculated from the Henderson-Hasselbalch equation employing a $\mathrm{pK}^{\prime}$ of 6.1 for carbonic acid, and an $\alpha$ equal to 0.0301 for plasma and 0.0309 for urine. The concentrations of sodium and potassium in plasma and urine were determined with an internal standard flame photometer. Chloride concentration in the plasma was determined on protein-free filtrates of plasma according to the method of Schales and Schales (8). A modified Volhard titration method (9) was used in determining the chloride concentrations of urine. The amount of each ion filtered per minute was calculated by multiplying its plasma concentration by the glomerular filtration rate. A Donnan distribution factor of 0.95 for $\mathrm{Na}^{+}$and $\mathrm{K}^{+}$and 1.05 for $\mathrm{Cl}^{-}$and $\mathrm{HCO}_{8}^{-}$was employed in this calculation. The rate of excretion of each ion was calculated by multiplying its urine concentration by the urine flow. The rate of reabsorption of water or any ion was taken as the difference between its rate of filtration and its rate of ex- cretion. To facilitate the analysis and the discussion of the results, the amount of a given ion reabsorbed per liter of glomerular filtrate was also calculated by dividing the rate of reabsorption of that ion expressed in $\mathrm{mEq}$. per $\mathrm{min}$. by the filtration rate expressed in $\mathrm{ml}$. per min. The concentration of each ion in the volume of water reabsorbed or "reabsorbate" was calculated by dividing the rate of reabsorption of each ion ( $\mathrm{mEq}$. per $\mathrm{min}$.) by the rate of water reabsorption ( $\mathrm{ml}$. per $\mathrm{min}$.), the resultant concentration being expressed in terms of $\mathbf{m E q}$. per $\mathrm{L}$.

\section{RESULTS}

Ten experiments were performed on ten animals. The results are summarized in Table $I$ and the protocol of one of these experiments is given in Table II. In four experiments (Nos. 1, 2, 3, and 4) the animals were studied, first, while breathing room air and receiving intravenously an infusion containing a 0.11 molar solution of sodium bicarbonate delivered at a rate of $6.4 \mathrm{ml}$. per minute, then while breathing the air- $\mathrm{CO}_{2}$ mixture and receiving the same infusion, and finally while continuing to breath the same air- $\mathrm{CO}_{2}$ mixture but receiving intravenously a 0.2 molar solution of $\mathrm{NaHCO}_{3}$ containing 5 Gram per cent of $\mathrm{NaCl}$. In one experiment (No. 5) the animal was studied initially while breathing the air- $\mathrm{CO}_{2}$ mixture and receiving intravenously a 0.11 molar solution of

TABLE II

Experiment illustrating the effect of sodium chloride infusion on the excretion and reabsorption of bicarbonate during acute respiratory acidosis

\begin{tabular}{|c|c|c|c|c|c|c|c|c|c|c|c|c|c|c|}
\hline \multirow[b]{3}{*}{$\begin{array}{l}\text { Time } \\
\text { min. }\end{array}$} & \multirow[b]{3}{*}{$\begin{array}{c}\text { GFR } \\
m l . / \\
m i n .\end{array}$} & \multirow{3}{*}{$\begin{array}{l}\text { Urine } \\
\text { flow } \\
\text { ml./ } \\
\text { min. }\end{array}$} & \multirow{3}{*}{$\begin{array}{c}\text { Reab- } \\
\text { sorbate } \\
\text { volume } \\
\text { ml./ } \\
\text { min. }\end{array}$} & \multirow{2}{*}{\multicolumn{3}{|c|}{ Plasma }} & \multirow{2}{*}{\multicolumn{3}{|c|}{ Urine }} & \multicolumn{5}{|c|}{ Bicarbonate* } \\
\hline & & & & & & & & & & \multirow{2}{*}{$\begin{array}{c}\text { Fil- } \\
\text { tered } \\
\mu E q . / \\
\text { mix. }\end{array}$} & \multirow{2}{*}{$\begin{array}{c}\text { Ex- } \\
\text { creted } \\
\mu E q . / \\
\text { min. }\end{array}$} & \multirow{2}{*}{$\begin{array}{c}\text { Reab- } \\
\text { sorbed } \\
\mu E q . / \\
\text { min. }\end{array}$} & \multirow{2}{*}{$\begin{array}{l}\text { Reab- } \\
\text { sorbed } \\
\text { per L. } \\
\text { filt. } \\
m E q .\end{array}$} & \multirow{2}{*}{$\begin{array}{c}\text { Conc. } \\
\text { in } \\
\text { reab- } \\
\text { sorbate } \\
\text { mEq./ } \\
L .\end{array}$} \\
\hline & & & & $\mathrm{pH}$ & $\begin{array}{c}\mathrm{HCO}_{8}- \\
m E_{q .} / \\
L .\end{array}$ & $\underset{\mathrm{H}_{\mathbf{g}}}{\mathrm{pCO}}$ & $\mathrm{pH}$ & $\begin{array}{c}\mathrm{HCO}_{3}^{-} \\
m E q . / \\
L .\end{array}$ & $\underset{\mathrm{Hg}}{\mathrm{pCO}_{2}}$ & & & & & \\
\hline
\end{tabular}

Dog 10,, $15.9 \mathrm{Kg} .$, breathing room air

0-8 prime: $400 \mathrm{ml}$. $0.375 \%$ Creatinine in $1.25 \% \mathrm{NaHCO}_{3}$

8 Begin infusion: $0.081 \%$ Creatinine in $1.175 \% \mathrm{NaHCO}_{3}$ at $18.5 \mathrm{ml}$. per min.

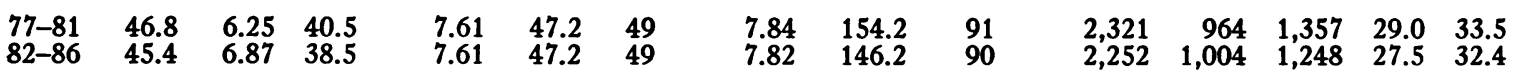

86 Begin inhale $10 \% \mathrm{CO}_{2}$ and $90 \%$ air for duration of experiment

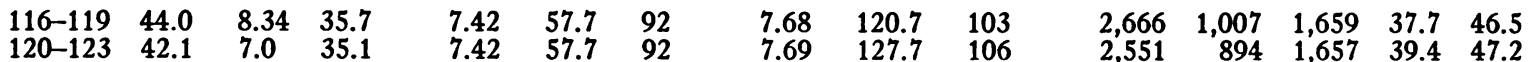

123.5 prime: $45 \mathrm{ml}$. of $3.33 \% \mathrm{NaCl}$

124 Change infusion to: $0.278 \%$ Creatinine and $2.3 \% \mathrm{NaHCO}_{3}$ in $5 \% \mathrm{NaCl}$ at $5.4 \mathrm{ml}$. per min.

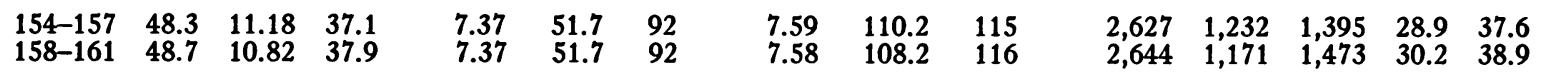

* See methods section for calculations of derived data. 
$\mathrm{NaHCO}_{3}$ administered at the rate of $6.4 \mathrm{ml}$. per minute. The chloride loading was then accomplished first by the administration of a 0.2 molar solution of $\mathrm{NaHCO}_{3}$ containing 4.35 Gram per cent of $\mathrm{NaCl}$ at the same rate, then by changing the infusion to a 0.2 molar solution of $\mathrm{NaHCO}_{3}$ containing 4.0 Gram per cent of $\mathrm{NaCl}$ and 0.5 Gram per cent of $\mathrm{KCl}$ delivered at the same rate of $6.4 \mathrm{ml}$. per min. Because the urine flow always rose sharply in these first five experiments when the hypertonic chloride infusion was given, an attempt was made to prevent this in the last five experiments (Nos. 6, 7, 8, 9, and 10) by administering a 0.11 to 0.14 molar solution of $\mathrm{Na}$ $\mathrm{HCO}_{3}$ at higher rates, i.e., 11 to $18.5 \mathrm{ml}$. per min. The chloride loading was then achieved by administering a 0.2 to 0.27 molar solution of $\mathrm{Na}$ $\mathrm{HCO}_{8}$ containing 5 to $7.6 \mathrm{Gram}$ per cent of $\mathrm{NaCl}$ at slower rates of 3.2 or $5.4 \mathrm{ml}$. per min. In four of these last five experiments (Nos. 6, 7, 8, and 9) the initial period of breathing room air was omitted.

In all experiments, during chloride loading, the amount of chloride filtered and the amount of chloride excreted in the urine both increased. Concomitantly, moreover, the rate of chloride reabsorption increased, as well as the concentration of chloride in the reabsorbate and the amount of chloride reabsorbed per liter of glomerular filtrate.

In all experiments, the load of filtered bicarbonate remained essentially unchanged during chlo-

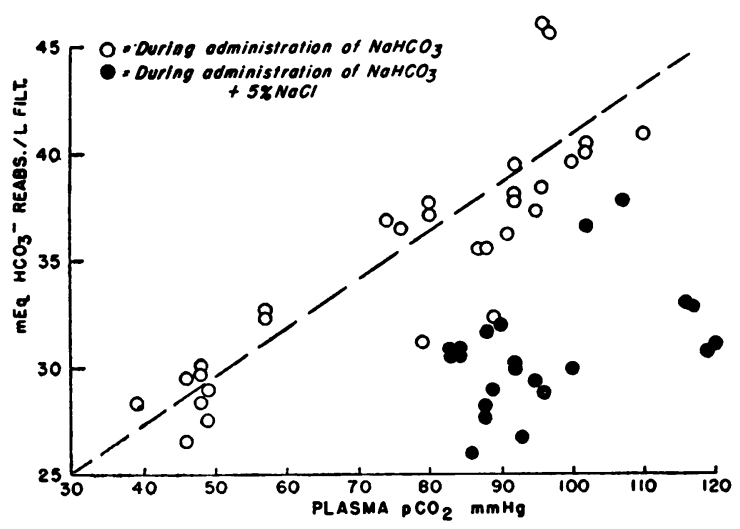

Fig. 1. Relationship Between Plasma $\mathrm{CO}_{2}$ Tension and Amount of Bicarbonate Reabsorbed per Liter of Glomerular Filtrate in Acute Respiratory ACIDOSIS BEFORE AND DURING INFUSION OF SODIUM Chloride ride loading, rising slightly in four experiments (Nos. 4, 5, 9, and 10) and decreasing slightly in six experiments (Nos. 1, 2, 3, 6, 7, and 8). In all experiments, however, whether the filtered bicarbonate slightly rose or decreased, the amount of $\mathrm{HCO}_{3}^{-}$excreted in the urine increased during chloride loading and the amount of $\mathrm{HCO}_{3}^{-}$reabsorbed per liter of glomerular filtrate decreased.

As can be seen in Table I, bicarbonate reabsorption increased as the plasma $\mathrm{pCO}_{2}$ rose, which confirms the work of other investigators $(2,3,10)$. During chloride administration, however, there occurred a fall in the rate of bicarbonate reabsorption and a rise in the bicarbonate excretion, despite the persistence in the elevation of the plasma $\mathrm{CO}_{2}$ tension. Figure 1 expresses graphically the relationship between the plasma $\mathrm{pCO}_{2}$ and the amount of bicarbonate reabsorbed per liter of glomerular filtrate during the administration of the air $-\mathrm{CO}_{2}$ mixture and the infusion of bicarbonate, both before and during chloride loading. The results observed before chloride loading are similar qualitatively and quantitatively to those reported by Brazeau and Gilman (2) as well as Dorman. Sullivan, and Pitts (3). The points representing such clearance periods are closely grouped along a straight line. However, the points representing the relationship between plasma $\mathrm{pCO}_{2}$ and the amount of $\mathrm{HCO}_{3}{ }^{-}$reabsorbed per liter of glomerular filtrate during chloride loading are aberrant in their location from the first group of points. Indeed, during chloride administration, even at $\mathrm{CO}_{2}$ tensions ranging between 90 and $100 \mathrm{~mm}$. $\mathrm{Hg}$, bicarbonate reabsorption falls to between 25 and 30 $\mathrm{mEq}$. per liter of glomerular filtrate, values only found at $\mathrm{CO}_{2}$ tensions of 35 to $50 \mathrm{~mm}$. $\mathrm{Hg}$ before the chloride administration.

Plasma potassium levels were consistently between 1.8 and $2.8 \mathrm{mEq}$. per $\mathrm{L}$. throughout all experiments with the exception of the final period of experiment No. 5 when the dog received $\mathrm{KCl}$ incorporated into the chloride infusion. Urine potassium excretion, with this latter period excepted, ranged between 35 and $104 \mu \mathrm{Eq}$. per min. Both blood and urine values remained very steady throughout each experiment and potassium excretion did not appear to be influenced either by elevation of $\mathrm{CO}_{2}$ tensions or by the combination of elevated $\mathrm{PCO}_{2}$ and chloride loading. 


\section{DISCUSSION}

The data presented above indicate that during acute respiratory acidosis, the renal excretion of bicarbonate was significantly increased by acute elevation of the plasma chloride concentration. Since the filtered load of bicarbonate remained essentially unchanged following the chloride infusions, the increased rate of bicarbonate excretion was entirely due to a reduction in the renal tubular reabsorption of bicarbonate. This occurred despite a tendency for extracellular $\mathrm{CO}_{2}$ tension to increase during the chloride loading. There seem to be several theoretically possible explanations for this increase in $\mathrm{HCO}_{3}^{-}$excretion: 1) Chloride loading interfered with $\mathrm{H}^{+}$secretion by the renal tubular cells, less $\mathrm{HCO}_{3}{ }^{-}$was converted to $\mathrm{CO}_{2}$ and $\mathrm{H}_{2} \mathrm{O}$, more became available in the tubular fluid and was excreted as $\mathrm{NaHCO}_{3} ; 2$ ) Chloride loading did not interfere either actively or directly with the reabsorption of $\mathrm{HCO}_{3}{ }^{-}$but promoted an osmotic diuresis which caused more of the filtered $\mathrm{HCO}_{3}{ }^{-}$to be excreted; 3 ) The increase in chloride filtration and the subsequent increase in $\mathrm{Cl}^{-}$reabsorption interfered directly with $\mathrm{HCO}_{3}{ }^{-}$reabsorption; or 4$) \mathrm{HCO}_{3}^{-}$was actively secreted by the tubular cells.

It is unlikely that $\mathrm{H}^{+}$secretion was depressed by chloride loading in view of the fact that urine $\mathrm{pH}$ decreased and urine $\mathrm{pCO}_{2}$ increased in most experiments following the chloride loading. The fall in urine $\mathrm{pH}$ per se, in alkaline urines such as these, could be explained solely by the fall in $\mathrm{HCO}_{3}^{-}$concentration due to dilution (i.e., osmotic diuresis) since the tubules are freely permeable to $\mathrm{CO}_{2}$. However, the rise in urine $\mathrm{CO}_{2}$ tension to values greater than that of the arterial plasma in the face of rising urine flows can best be explained on the basis of hydrogen ion addition to these urines resulting in titration of $\mathrm{HCO}_{3}{ }^{-}$to form additional carbonic acid. Such $\mathrm{H}^{+}$addition could come from distal tubular secretion of $\mathrm{H}^{+}$into a urine containing increasing amounts of $\mathrm{HCO}_{3}^{-}$, or it could come from an increase in the excretion of acid buffers into this urine. Total buffer concentration was not measured in these experiments; but the concentration of one buffer (i.e., creatinine) was measured and found to decrease. It does not seem unreasonable, therefore, to presume that the concentration of other buffers would like-

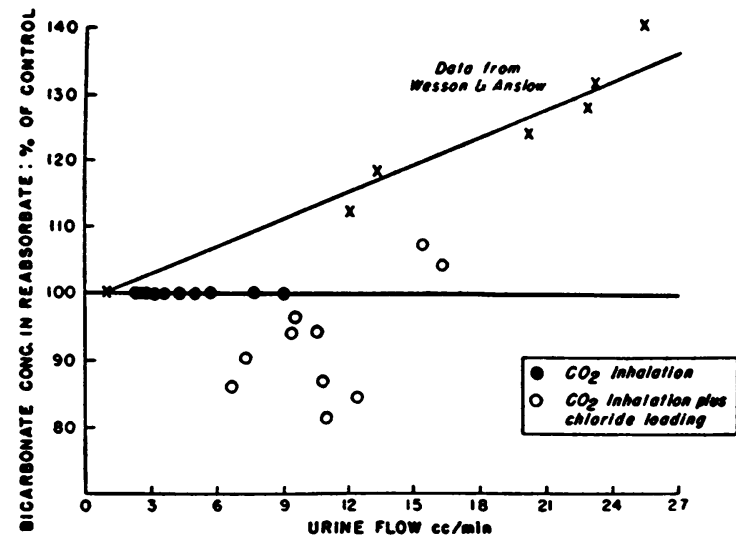

Fig. 2. Per Cent Change in Bicarbonate Concentration of Reabsorbate Plotted against Urine FLow

The points on the 100 per cent line represent control values observed during $\mathrm{CO}_{2}$ inhalation. The open circles are the values obtained following the chloride loading, during continued $\mathrm{CO}_{2}$ inhalation. The data from Wesson and Anslow (12) was obtained during mannitol diuresis under conditions of normal $\mathrm{CO}_{2}$ tension.

wise decrease as urine flow increased and hence the rise in urine $\mathrm{pCO}_{2}$ appears to be the result of continued secretion of hydrogen ion into a highly alkaline urine. The decrease in $\mathrm{HCO}_{3}{ }^{-}$reabsorption following the chloride loading in the face of continued $\mathrm{H}^{+}$secretion must therefore be explained on the basis of some other mechanism.

It is difficult to hold that osmotic diuresis was responsible for the decreased reabsorption of bicarbonate because in 8 of 10 experiments there was a fall in the concentration of bicarbonate in the reabsorbate following the chloride loading. This occurred despite marked increases in urine flow and decreases in reabsorbate volume in four of these experiments (Nos. 1, 2, 5, and 9). If it is allowed that there is normally no limitation to the concentration of $\mathrm{HCO}_{3}^{-}$in the reabsorbate one would expect that under a constant rate of $\mathrm{HCO}_{3}^{-}$ reabsorption (11) there would be an increase in $\mathrm{HCO}_{3}^{-}$concentration of the reabsorbate as the urine volume increases and the volume of the reabsorbate falls. This has been shown by Wesson and Anslow (12) to occur during mannitol diuresis. In Figure 2 is plotted the per cent change in the bicarbonate concentration of the reabsorbate following chloride loading compared with the data of Wesson and Anslow (12) obtained under conditions of mannitol loading. During mannitol diu- 
resis there is a progressive linear increase in the bicarbonate concentration of the reabsorbate as urine flow increases, whereas following chloride loading in most of our experiments there is a fall in the bicarbonate concentration of the reabsorbate as urine flow increases. Since it has also been shown that osmotic diuresis per se does not particularly increase the excretion of bicarbonate $(13,14)$ it is apparent that the increases in the excretion of bicarbonate and decreases in the reabsorption of bicarbonate following chloride loading are brought about by some other mechanism.

There remains the theoretical possibility that bicarbonate may have been secreted by the tubular cells and that such a secretion of $\mathrm{HCO}_{3}{ }^{-}$by the tubular cells may have been increased by chloride loading, thus accounting for the observed increase in excretion and apparent decrease in reabsorption of bicarbonate during chloride loading. It can only be stated in this regard that there is no direct experimental evidence that such a mechanism exists.

It appears then that during acute respiratory acidosis an increase in the amount of chloride reabsorbed interferes with the reabsorption of bicarbonate. This is in accord with the earlier observations made by Pitts and Lotspeich (4) on animals with presumably normal $\mathrm{CO}_{2}$ tensions and is entirely consonant with the theory that there is competition between these two ions for a common reabsorptive transport mechanism. Indeed, it was originally suggested by these investigators that a dual process of bicarbonate reabsorption existed whereby most of the bicarbonate filtered at the glomerulus was reabsorbed by a specific anion transport in the proximal tubule. In this schema some of the bicarbonate ions not reabsorbed by the proximal tubule were reabsorbed in the distal tubule by a process involving exchange of $\mathrm{H}^{+}$ions originating within the tubular cells for $\mathrm{Na}^{+}$ions derived from the tubular urine.

It was later observed by Berliner (1) that following the administration of Diamox ${ }^{\otimes}$, the amount of the additional bicarbonate excreted in the urine was too great to be accounted for solely by the abolition of the distal hydrogen ion secretory mechanism. Berliner therefore proposed that bicarbonate reabsorption throughout the entire renal tubule was dependent upon the hydrogen ion secretion mechanism. This concept was supported by the recent studies of Brazeau and Gilman (2) and Dorman, Sullivan, and Pitts (3). Working independently, these investigators noted that as the $\mathrm{CO}_{2}$ tension of the extracellular fluid is raised, there is a concomitant linear increase in renal bicarbonate reabsorption. Since, presumably, $\mathrm{H}^{+}$ secretion by the renal tubules increases with increasing $\mathrm{pCO}_{2}$, they concluded that the increased rate of $\mathrm{HCO}_{3}{ }^{-}$reabsorption could best be explained by the assumption that the reabsorptive mechanism was entirely dependent upon the exchange of $\mathrm{H}^{+}$ions derived from carbonic acid in the tubular cells for fixed base of filtered bicarbonate in the tubular urine.

This $\mathrm{H}^{+}-\mathrm{B}^{+}$exchange theory of the renal regulation of bicarbonate excretion however, does not adequately account for the reciprocal changes in the plasma $\mathrm{HCO}_{3}$ - levels which accompany rises and falls in plasma $\mathrm{Cl}^{-}$levels. Indeed, it was this phenomenon, together with the observation that increased $\mathrm{Cl}^{-}$loading facilitated $\mathrm{HCO}_{3}$ - excretion, which led Pitts and Lotspeich (4) to postulate specific ionic reabsorption of bicarbonate by the proximal tubule. Moreover, although the theory adequately explains the renal compensations in acute and chronic respiratory acidosis and alkalosis, it does not satisfactorily explain the renal compensations for metabolic acidosis and alkalosis, as pointed out by Brazeau and Gilman (2) as well as by Relman, Etsten, and Schwartz (10). One wonders if the main weakness of the theory does not lie in the assumption that $\mathrm{HCO}_{3}$ - reabsorption can only occur through $\mathrm{H}^{+}$ion secretion. If this were so, one would expect that the urine $\mathrm{pH}$ would decrease as $\mathrm{HCO}_{3}^{-}$reabsorption increases. That this is not the case is apparent from analysis of the data published to date (1-3). In fact, in experiments on dogs with chronic respiratory acidosis (15), it can be seen that as $\mathrm{HCO}_{3}^{-}$reabsorption increased with increasing plasma $\mathrm{pH}$ levels, the urine became more alkaline and the $\mathrm{pCO}_{2}$ of the urine declined.

It would appear then, that bicarbonate reabsorption is not entirely due to $\mathrm{H}^{+}-\mathrm{B}^{+}$exchange since it is possible to elicit a reciprocal relationship between chloride and bicarbonate reabsorption and to induce an increase in the reabsorption of one of these ions and a decrease in the reabsorption of the other while the $\mathrm{pCO}_{2}$ remains constant. Furthermore, this reciprocal relationship 
was observed in the presence of two factors which have been demonstrated both to reduce chloride reabsorption and to increase bicarbonate reabsorption, i.e., (a) high plasma $\mathrm{CO}_{2}$ tensions (2, 3 ), and (b) a probable state of potassium depletion $(16,17)$ resulting from the infusion of large amounts of sodium bicarbonate, at least as judged by the low plasma potassium levels.

\section{SUMMARY AND CONCLUSIONS}

1. In acute experiments performed on anesthetized dogs, it has been observed that:

A. In acute respiratory acidosis, the amount of bicarbonate excreted in the urine decreases and the amount of bicarbonate reabsorbed increases, whereas the amount of chloride excreted decreases and the amount of chloride reabsorbed decreases;

B. The administration of chloride during respiratory acidosis results in an increase in the amount of bicarbonate excreted and a decrease in the amount of bicarbonate reabsorbed.

2. The phenomena observed suggest the possibility that at least part of the reabsorption of bicarbonate is ionic and not dependent upon hydrogen ion secretion by the tubule. This part of the bicarbonate reabsorption is affected by the reabsorption of chloride in such a manner as to suggest competition between the chloride and bicarbonate ions for a common reabsorptive transport mechanism in the tubule.

\section{ACKNOWLEDGMENT}

We gratefully acknowledge the technical assistance of Miss Lydia Gluchowa.

\section{REFERENCES}

1. Berliner, R. W., Renal secretion of potassium and hydrogen ions in Symposium on Secretion of Electrolytes, American Physiological Society, Federation Proc., 1952, 11, 695.
2. Brazeau, P., and Gilman, A., Effect of plasma $\mathrm{CO}_{2}$ tension on renal tubular reabsorption of bicarbonate. Am. J. Physiol., 1953, 175, 33.

3. Dorman, P. J., Sullivan, W. J., and Pitts, R. F., The renal response to acute respiratory acidosis. J. Clin. Invest., 1954, 33, 82.

4. Pitts, R. F., and Lotspeich, W. D., Bicarbonate and the renal regulation of acid-base balance. Am. J. Physiol., 1946, 147, 138.

5. Kennedy, T. J., Jr., Hilton, J. G., and Berliner, R. W., Comparison of inulin and creatinine clearance in the normal dog. Am. J. Physiol., 1952, 171, 164.

6. Van Slyke, D. D., and Neill, J. M., The determination of gases in blood and other solutions by vacuum extraction and manometric measurement. I. J. Biol. Chem., 1924, 61, 523.

7. Rosenthal, T. B., The effect of temperature on the $\mathrm{pH}$ of blood and plasma in vitro. J. Biol. Chem., 1948, 173, 25.

8. Schales, O., and Schales, S. S., A simple and accurate method for the determination of chlorides in biological fluids. J. Biol. Chem., 1941, 140, 879.

9. Volhard, J., Ueber eine neue Methode der maassanalytischen Bestimmung des Silbers. J. Prakt. Chem., 1874, 9, 217.

10. Relman, A. S., Etsten, B., and Schwartz, W. B., The regulation of renal bicarbonate reabsorption by plasma carbon dioxide tension. J. Clin. Invest., 1953, 32, 972.

11. Smith, H. W., The Kidney. New York, Oxford University Press, 1951.

12. Wesson, L. G., Jr., and Anslow, W. P., Jr., Excretion of sodium and water during osmotic diuresis in the dog. Am. J. Physiol., 1948, 153, 465.

13. Mudge, G. H., Foulks, J., and Gilman, A., Effect of urea diuresis on renal excretion of electrolytes. Am. J. Physiol., 1949, 158, 218.

14. Goodyer, A. V. N., Welt, L. G., Darragh, J. H., Abele, W. A., and Meroney, W. H., The effect of glucose diuresis on the renal excretion of sodium bicarbonate. J. Clin. Invest., 1952, 31, 632 (abstract).

15. Sullivan, W. J., and Dorman, P. J., The renal response to chronic respiratory acidosis. J. Clin. Invest., 1955, 34, 268.

16. Cooke, R. E., Segar, W. E., Reed, C., Etzwiler, D. D., Vita, M., Brusilow, S., and Darrow, D. C., The role of potassium in the prevention of alkalosis. Am. J. Med., 1954, 17, 180.

17. Roberts, K. E., Randall, H. T., Sanders, H. L., and Hood, M., Effects of potassium on renal tubular reabsorption of bicarbonate. J. Clin. Invest., 1955, $34,666$. 